Artigos

\title{
A sociologia econômica de Simmel e Bourdieu Considerações para um programa de pesquisa
}

\section{The economic sociology of Simmel and Bourdieu} Considerations for a research program

Ricardo Visser*

\begin{abstract}
Resumo: O intento de adentrar algumas das premissas teóricas contidas nos escritos econômicos de Pierre Bourdieu e Georg Simmel tem como base a compreensão da importância da investigação sobre práticas e condições econômicas. Ao invés de pressupor, de um lado, que práticas são apenas reflexos inerciais de condições econômicas, e, de outro, que práticas determinam as condições, mobiliza-se a ideia de uma dinâmica de condicionamento mútuo. Assim sendo, o acesso ao comportamento prospectivo com o dinheiro depende de condições prévias mais ou menos estáveis, permitindo ao agente perceber o uso potencial do dinheiro, não mais circunscrito ao imediato. A reconstrução dos dois autores tem essa preocupação como pano de fundo, buscando contribuir à renovação da teoria de classes.
\end{abstract}

Palavras-chave: Bourdieu. Simmel. Práticas econômicas. Teoria de classes. Desigualdade.

Abstract: The analysis of some theoretical arguments in the economic writings of Pierre Bourdieu and Georg Simmel assumes the importance of the investigation on economic practices and conditions. Instead of presupposing, on one hand, that practices are a mere reflex of economic conditions and, on the other, that practices determine conditions, we adhere to the idea of mutual conditioning. In this sense, the access to prospective economic practices depend on relatively stable conditions in which the potential usage of money flourishes. The reconstruction of the works of both mentioned authors follows this path by trying to contribute to the renewal of class theory.

Keywords: Bourdieu. Simmel. Economic practices. Class theory. Inequality.

\footnotetext{
* Doutor em Sociologia pela Universidade Federal de Juiz de Fora (MG, Brasil), com estágio sanduíche na Humboldt Universität zu Berlin, Alemanha, faz estágio pós-doutoral no PPG em Direito da Universidade Estadual do Rio de Janeiro (Uerj) no Rio de Janeiro, RJ, Brasil. Participou da pesquisa que culminou no livro Reproduktion sozialer Ungleichheit in Deutschland (Rehbein, 2015) e entre 2015-2016 trabalhou no Instituto de Pesquisa Econômica Aplicada<ricardovis@gmail.com>.
}

Civitas, Porto Alegre, v. 17, n. 2, e60-e78, maio-ago. 2017 


\section{Introdução}

$\mathrm{Na}$ sociologia clássica, as reflexões em torno da formação da esfera econômica sempre ocuparam o epicentro teórico. Marx (Honneth, 1980, p. 189) buscou costurar uma filosofia da história da espécie humana com uma ontologia do trabalho, cuja premissa básica centra-se na precedência heurística do trabalho produtivo, capaz de objetivar a natureza através de habilidades e máquinas. Em distinção a ele, Simmel (2009) e Bourdieu (1977; 2000) interpretaram a economia moderna tanto sob a maneira pela qual ela permite ou inibe uma experiência prospectiva com o tempo, condicionando nossas categorias avaliativas, quanto através do elo entre mercado e estado, na medida em que não constituem domínios de todo separados na realidade social. No limite, o estado, se arrolarmos o exemplo de uma concessão pública, legitima o interesse econômico oficial.

Marx, ao opor, em seu materialismo histórico, bases produtivas e configurações culturais e simbólicas, encontra a primazia da esfera econômica, calcada na ideia de que, tomado como atividade definidora daquilo que possibilita organizações coletivas humanas, o trabalho produtivo constitui o fundamento determinante do processo de reprodução social. Ele não tão somente é observável em sua forma presente, mas igualmente passada, ao passo que a acumulação de conhecimento técnico, seja artesanal ou científico, permite a construção de maquinário ou instrumentário, acelerando a exploração do trabalho vivo, transformando-o, após seu ciclo de valorização, em capital financeiro. Ele também pode torná-lo obsoleto, forçando a emergência de novas formas de trabalho. Nesse caso, faz-se necessário um nexo causal, locupletando-se no encontro de um fundamento conceitual à luz do qual se deduz o restante dos fenômenos e eventos na sociedade. Marx localiza uma estrutura profunda da sociedade (Unger, 2001, p. xxix) na categoria de trabalho enquanto objetivação transformadora da natureza por um sujeito produtor, sendo capaz de reaplicar conhecimento adquirido por meio dessa atividade prático-cognitiva.

A ideia de uma estrutura profunda do capitalismo encontra ressonância numa categoria indiferenciada de dominação: quem concentra os meios de produção e o capital econômico controla automaticamente todas as outras espécies de capital válidas no campo econômico: o simbólico (confiança), tecnológico, jurídico, o informacional, financeiro, o político (capacidade de influência na política econômica) e etc. De acordo com tal prisma teórico, a dominação social poderia ser deduzida de uma única imposição hierárquica (Boyer, 2015, p. 30-31). 
Substitui-se a ideia de causa ou substância pela "multicausalidade", tão translúcida no "relacionalismo" de Simmel (2009, p. 104-105), almejando um perspectivisimo, amparado nas afinidades qualitativamente intercambiáveis entre os fenômenos e eventos socialmente significantes; sentido é relação. Para Bourdieu, cuja vantagem é reavivar o casamento entre dominação de classes, a ordem institucional e uma teoria prática da socialização, é preciso apreender como os registros de dominação e manutenção de poder, como escola, política, economia, arte e etc., operam segundo regras próprias. Diante deste preceito, o campo econômico é global, mas especializado dentro da divisão do trabalho da dominação e seu respectivo circuito de legitimação.

À primeira vista, o estranhamento dá-se a partir de inversões, como enxergar o mercado através de fatores não imediatamente econômicos, e não apenas como uma relação mecanicamente autônoma entre oferta, demanda e alocação eficiente de capital. Em contrapartida, os dois investigam como a moda pode, ao orientar-se por meio da distinção e assimilação das classes, estabilizar oferta e demanda em sua incessante necessidade de criar a sensação de novidade (Simmel, 1995, p.11-12); ou: como, de acordo com Bourdieu, o desejo de obter uma casa própria pode estar ligado à crescente expansão do modelo matrimonial citadino na sociedade global, fazendo adormecer as antigas formas familiares camponesas (Sousa, 2012, p. 183-184). Ou ainda: como as elites econômicas não expressam seus interesses diretamente via mercado, dado que ele não comporta imediatamente um espaço próprio de representação e construção simbólica de suas formas possíveis de organização. Dependem do lobby na política, da ciência econômica conservadora e do poder de legitimação, isto é, violência simbólica na esfera pública, tornando, por exemplo, as teses que sustentam uma política econômica neoliberal como naturais e inevitáveis. A contradição reside na tentativa de despolitização da economia na esfera pública.

Feita essa distinção mais geral entre dois aportes teóricos, o artigo contará com três partes: nas primeiras duas adentrar-se-á a obra de Simmel e Bourdieu com o fito de compreender suas visões sobre economia e sociedade. Por fim, buscar-se-á uma aplicação dessas teses à temática das práticas econômicas. Ao invés de conceber condições econômicas, como faz o materialismo, como causa inercial, entendemos que práticas detêm uma dinâmica singular, no entanto, elas por si só, como crê boa parte do pensamento liberal sobre "saúde financeira", não têm poder de determinar ou constituir condições econômicas favoráveis. 


\section{Simmel e a psicologia social da modernidade}

Os escritos relativos ao dinheiro, em Simmel, amadurecem a partir do momento em que começa a inclinar-se à união entre filosofia social, sociologia e psicologia. Contudo, sua concepção do que seja psicologia não deve separar-se nem da categoria de interação (Wechselwirkung) e muito menos do conceito de cultura (Kultur). Isto posto, Simmel não se ampara numa noção do sujeito solipsista, isolado em meio a entidades mentais privadas. Ao contrário, só se pode verdadeiramente falar em estados afetivos ou ontológicos (Seinszustände) quando se leva a ideia de que os agentes são portadores de conteúdos culturais (Kulturträger) e imersos em processos de interações significativos, como afirmou Siegfried Kracauer (1977, p. 210-211). Logo, psicologia e sociologia, são complementares, de modo que um estado afetivo engloba uma provável função ou posição social. Dá-se, assim, importância ao caráter intersubjetivo de formas de pensamento, visto que se encontram num pano de fundo compartilhado, formando quase sempre algum tipo sociação (Vergesellschaftung), como cooperação ou competição. Nem indivíduo e nem sociedade existem enquanto unidades abstratas sobrepostas; elas refletem processos nos quais interações e práticas se desenrolam.

Este ponto de vista foi censurado como "psicologismo" tanto por Durkheim (2007, p.34), já que não se apoiava em fatos sociais exteriores, objetivos e institucionalizados, quanto por Weber, ao postular que o curso normal de uma ação não evoca um estado mental ou afetivo; a menos que ela seja mal compreendida (Nedelmann, 1988, p. 14). O interesse em adentrar os aspectos psicológicos das interações normalmente era descartado, visto que a separação entre pré-noções espontâneas de seu estado afetivo não exibe qualquer validade epistemológica ou correspondência objetiva. Ainda que se corra o risco de, de fato, recair sobre o "psicologismo", o empenho de Simmel era apontar para uma teoria prática da socialização. Ao tratar do tema, ele afirma:

[...] O sujeito não contrapõe-se, aqui, a um objeto a partir do qual ele constitui uma concepção teórica, mas a consciência da sociação $e ́$ imediatamente seus portadores ou seu significado interno. Trata-se de um processo de interação que não é abstrato para o indivíduo, embora seja capaz de tomar uma expressão abstrata (Simmel, 1992, p.47). (tradução minha).

Em passagem muito complementar à de Bourdieu, falta a Simmel, apenas a conexão do processo de interiorização da cultura com o de incorporação. Tal introito foi necessário, pois, ao entendermos as intenções iniciais do filósofo 
social alemão, conseguimos justificar sua eleição pela esfera da circulação do dinheiro. Não se pode, entretanto, atribuir a Simmel, uma contraposição nua e crua a Marx, mas uma complementação.

No âmbito da obra Filosofia do dinheiro (2009), o que lhe interessa é: a) delinear uma teoria do valor qualitativo; b) sua subordinação às formas quantitativas e abstratas de valor da economia monetária moderna (o dinheiro); c) como tal sobreposição dos valores quantitativos aos qualitativos influencia interações, a maneira de sentir e avaliar dos modernos.

Se levarmos em conta seu corolário desenvolvido sobre a gênese dos valores qualitativos, duas teses antropológicas sobre a agência são centrais: a) a dotação de uma sensibilidade distintiva (Unterschiedsempfindlichkeit). Enquanto se distinguem, conferimos valor aos objetos, aos outros, erigindo, assim, uma cultura. $\mathrm{O}$ valor não é nem uma propriedade aderente e nem isolada de um objeto, mas é dependente da capacidade de atribuição ou estima (Schätzung) qualitativa e relacional; b) Tal possibilidade de atribuir qualidade aos objetos apenas emerge quando o gozo (Genuss) torna-se mediado por um anseio (Begehren):

[...] Que o valor não surge na unidade contínua do momento de gozo, mas ao passo que seu conteúdo desprende-se como objeto do sujeito e a ele como ansiado se contrapõe. Para ganhá-lo necessita-se da superação de distâncias, obstáculos e dificuldades. [...] O valor surge nesse mesmo processo de diferenciação, com o "eu" desejante como seu correlato (Simmel, 2009, p. 35).

A interpretação decorrente dessa direção argumentativa é que o valor surge quando o gozo não é imediato, instaurando uma distância temporal entre desejo e realização, além de uma diferenciação entre sujeito desejante, pensante e objeto intencionado. Quanto mais longo é este ínterim, mais complexo é o nexo teleológico e o encadeamento entre as etapas até que se atinja a realização. Daí extrai-se a ideia de que: quanto mais complexa uma formação social é, mais a realização de nossos desejos é mediada e penetrada por fantasias, expectativas, representações e projeções. Essa posição também pode ser compreendida como uma tentativa de síntese entre duas teorias da diferenciação entre sujeito e objeto: o racionalismo e o vitalismo. Para o último, existe uma fusão afetiva do indivíduo com o mundo e a natureza. Já para o racionalismo (kantiano), a representação consciente constitui, a partir do pensamento abstrato, a mediação entre sujeito e objeto (Simmel, 1995). Conquanto, embora considere emoções e desejo, sua teoria da ação toma o homem como destinado a estipular fins (Simmel, 1899). 
Talvez, o tema mais significativo de sua obra seja a intersecção entre o advento da economia monetária madura (Frisby, 1986, p. 80) e a vida interior (Innenleben). O propósito de Simmel (2009, p. 17) é construir uma ponte entre fenômenos econômicos e o desenvolvimento da cultura espiritual, de modo que crescentemente a forma monetária de um valor penetra no cotidiano do homem moderno. Com o advento do capitalismo industrial, ele verifica como o dinheiro tende a se desvencilhar do seu valor de substância (Substanzwert), para desempenhar um valor de função (Funktionswert), posto que não se atrela mais a um valor qualitativo (valor de uso), como no caso do sal ou do ouro. Enquanto papel moeda e representante de um valor puramente quantitativo e, por isso, abstrato, o dinheiro torna-se o meio de troca capaz de conferir comensurabilidade niveladora às valorações qualitativas. Por ser amorfo, isto é, não portar substância própria, é capaz de representar todas as outras, colocando-as em relação.

Como resultante da alomorfia do dinheiro numa forma (um imperativo sistêmico que molda procedimentos institucionais, interações e expectativas), Simmel advoga a tese segundo a qual a prevalência de uma valoração (Wertung) em termos quantitativos fortalece o espírito do cálculo e espraia uma atitude prático-instrumental até nas regiões mais ínfimas do cotidiano. Eis, então, a base de sua perspectiva trágica sobre a modernidade porquanto o dinheiro, de meio de troca abstrato, se torna o fim objetivo de anseios e realizações. A inversão entre meios e fins carrega consequências psicológicas contundentes em seu bojo. Se o dinheiro na economia moderna significa um processo de abstração no qual a cultura não se encontra mais rente às particularidades da experiência imediatamente sensível, seu racionalismo estimula uma vida psíquica nervosa e indiferente. Como manifestação psicológica desse contexto surgem alguns tipos sociais, como o cínico:

[...] Seu sentimento de vital torna-se adequadamente expresso quando ele explicita teórica e praticamente, como ilusão, a insignificância até mesmo dos valores mais elevados. À tal postura não se pode atribuir nada além da capacidade que o dinheiro tem em reduzir valores elevados e irrelevantes à mesma forma de valor [...], nivelando-os (Simmel, 2009, p. 383).

Como denominador comum dos valores qualitativos, o dinheiro nivela todas as tomadas de posição e todos os ideais. O cínico é aquele indiferente aos efeitos práticos de ideias. Para ele, tudo além da ordem estabelecida nada passa de uma utopia irrealizável porque todas as intenções se equivalem, todas hierarquias valorativas se deixam nivelar. Deontologicamente é um fatalista. 
Sob este prisma, o mesmo pode ser dito da prostituição na qual a troca do dinheiro pela entrega do corpo feminino enseja não apenas a subjugação subjetiva unilateral da prostituta aos desejos do cliente, mas impede simultaneamente a formação de uma esfera íntima entre os dois. Simmel procede com os tipos sociais para ilustrar como o dinheiro afeta a estrutura da personalidade moderna, principalmente sua habilidade de distinção qualitativa e de aprofundamento das relações pessoais.

Há ainda outro ponto menos recorrente na obra: como as classes sociais, cuja experiência social é hierarquizada, agem com o dinheiro? No tocante ao desenvolvimento de um programa de pesquisa, esse tema nos é deveras caro. Algumas premissas podem ser elencadas:

a) A conexão entre posição de classe e a chance de estabelecer, em vista de condições econômicas mais ou menos confortáveis, práticas econômicas relativamente "livres" não diretamente limitadas e prédeterminadas pelas urgências econômicas (Simmel, 2009, p.317). Enquanto os pobres encontram os fins (Zwecke) de uso com o dinheiro pré-definidos pelas condições, os ricos dispõem do alargamento do uso potencial do dinheiro. Trata-se do alargamento do poder decisório sobre o dinheiro, incorrendo na compreensão de seu uso potencial. Assim, o fortalecimento da antecipação do futuro econômico em longo prazo aproxima as categorias dinheiro e poder, primeiramente, sob a forma de seu exercício e, em seguida, através de sua existência material direta. Tais condições fortalecem o lado das práticas, pois abrem mais margem para o poder decisório.

b) A maneira pela qual configurações favoráveis das condições e práticas econômicas alteram estados afetivos e cognitivos. Há uma conexão entre elas e nossa capacidade projetiva (Vorstellung), cujo limite é o sentimento sublimado de exercício de poder. Em tais situações, presencia-se o encurtamento paulatino entre expectativas e satisfações objetivas de um desejo ou necessidade.

c) A contradição acerca da vulnerabilidade do assalariamento com relação às inconstâncias sistêmicas da economia, como a inflação, visto que, por outro lado, ele pressupõe a liberdade de troca por mercadorias (Simmel, 2009, p. 526). Ele conjuga, por um lado, limitações objetivas, por outro, a liberdade decisória de dispor sobre ele;

d) a conexão entre manutenção de um estilo de vida e o salário, cuja conexão é tão mais independente do desempenho produtivo imediato quanto mais prestígio e poder estatutário uma profissão agrega (ibid., p. 530); 
Embora não fosse a preocupação original de Simmel, a relação entre dinheiro e certo pertencimento de classe assinala que, para além de uma expressão geral da vida mental e psíquica, com o dinheiro na modernidade existem experiências diferenciais, marcadas pelo acesso a determinadas condições e modos de ação. Assim, podemos falar numa configuração prática e psicológica legada por uma estrutura social, que não funciona uniformemente para todos, dado que não garante condições iguais de acesso a comportamentos valoráveis. Desse modo, por exemplo, a concorrência funda, na economia, a seletividade e a raridade do lucro, já que junto a ela encontramos mecanismos de proteção e encerramento, bem como de generalização, democratização e abertura. A fim de que seja acumulado por alguns, o capital deve ser efetivamente negado e restringido a outros (Simmel, 1992, p. 337). O mercado jamais prescinde de uma forma contingente de organização social.

A esse ponto, podemos distinguir entre duas molduras argumentativas: a primeira seria relativa à filosofia das formas de valor na modernidade, posto que o dinheiro, enquanto portador de um valor desforme, traz em seu bojo consequências concretas para a vida psíquica em geral. No segundo plano, adentra-se a concepção de que as práticas e a percepção com o dinheiro metamorfoseiam-se em função de formas contingentes de sociação, pertencimento, do estilo de vida, de um pano de fundo cultural e do posicionamento em relações de produção. $\mathrm{O}$ aspecto propriamente sociológico desse caminho investigativo consiste em priorizar a dinâmica mútua dos modos de ação econômica e seus condicionantes contextuais. Na conclusão veremos como este fito influencia a proposta para um programa de pesquisa.

\section{Bourdieu: o habitus e o campo econômico}

Nos estudos econômicos de Bourdieu (1977; 2000) encontramos a tentativa de desconstrução do paradigma (neo)clássico e liberal tanto ao nível da "ação" quanto da "estrutura". Enquanto as investigações versando sobre sub-proletariado argelino podem ser consideradas como os representantes do primeiro nível de análise, as investigações acerca do mercado imobiliário refletem a tentativa de compreensão das determinantes do campo econômico. Adverte-se, contudo, que nem sempre há pleno encaixe entre campo e habitus econômico, sendo, inclusive, possível a manutenção de contradições, revelando um estado de hysteresis, ou seja, um profundo descompasso entre expectativas subjetivas e condições objetivas. A razão disso é que a construção e a gênese do mercado capitalista ocorrem por meio de uma racionalidade histórica e nem tanto pelo atributo racional natural, contido na ação de todo agente econômico. 
Se no plano das interações a ideia é romper, em absoluto, com a premissa liberal de que uma ação econômica racional depende apenas do poder decisório do indivíduo isolado, noutro polo cabe à pesquisa comprovar que o mercado não apenas está ancorado na política, mas igualmente em organizações e instituições burocráticas (empresas) capazes de impor condições de mercado, condicionando preços, leis tributárias, aduaneiras, acesso a crédito e etc. Tal privilégio incute uma cláusula de vantagem temporal, isto é, a capacidade de antecipação aos concorrentes. Ao perseguir este horizonte teórico, admite-se que o ato fundador do mercado não é somente o lucro, mas as garantias mais ou menos estáveis das condições favoráveis de concorrência (na maioria das vezes sob proteção estatal). Portanto, a ideia de uma concorrência franca e meritocrática simplesmente não existe. A rigor, não existe mercado sem estado, uma vez que a chancela de legitimação de uma forma de organização do social da economia, isto é, de um estado da divisão do trabalho social, depende da política (capacidade de organização coletiva das categorias profissionais, a dinâmica das leis trabalhistas e etc.). Toda política econômica é também economia política.

Cabe ainda a explicitação de um pressuposto fundamental: o acesso a condições estáveis e práticas econômicas minimamente diferenciadas significa poder perceber o futuro no longo prazo. O futuro ao qual fazemos menção não repousa sobre uma extensão do presente, mas numa projeção abstrata, que, muitas vezes, não é passível de ser imaginada com precisão. Esclarecemos que o futuro como alongamento do presente corresponde à provisão, mas não à acumulação contínua. Aqui, Bourdieu e Simmel se encontram: a mitigação das incertezas temporais com relação às urgências econômicas torna oportuna a realização de expectativas, que, do contrário, permaneceriam infundadas e fantasiosas.

A crítica de Bourdieu à teoria liberal está calcada numa reversão teórica: não tomar o sujeito abstrato, baseado numa filosofia social transcendental, mas o sujeito econômico prático e contextualizado. Outro paradigma a ser superado é o culturalismo, cujos pressupostos supunham o mero "intercâmbio cultural" entre os camponeses e a ordem colonial francesa. Haveria, portanto, uma mera "fusão de horizontes" porquanto uma cultura se adaptaria e se adequaria à outra. O esforço bourdieusiano galga além: é preciso saber como a edificação de uma ordem econômica capitalista introduz uma nova forma de lidar com o tempo, ou seja, de estabelecer relações entre eventos (Elias, 1984, p. XVII).

A temporalidade não segue mais a reprodução circular da natureza, mas firma-se em relação ao futuro abstrato, tomado enquanto ambição de acumulação constante de capital econômico. Trata-se de uma forma linear do 
tempo, buscando a imposição de um sistema de significação próprio e não mais mediado pelos ciclos naturais. Eis a grande contradição do desenraizamento argelino: um cosmos econômico cada vez mais desenvolvido e maduro se estabelece, sem que o sub-proletariado disponha do aprendizado sobre como lidar com o futuro no longo prazo. Tem-se uma racionalização sistêmica cada vez mais nítida da economia, mas as classes marginalizadas não dispõem de disposições econômicas racionais. Há, então, a associação clara entre condições economicamente previsíveis e a capacidade de perceber e agir com o dinheiro tendo em visto o futuro de longo alcance. Apresenta-se, aqui, a íntima relação entre aquisição de um novo arcabouço cognitivo, afetivo e mental e o acesso a condições econômicos minimamente estáveis.

Ainda que Bourdieu não adentre especificamente nesse tópico, seria possível complementá-lo dizendo que todas as formas institucionalmente mediadas do capital econômico, para além da simples posse de dinheiro (renda garantida [Fromm, 1999], patrimônio rentável ou produtivo, investimentos financeiros e etc.), têm como correlato a expansão da percepção do futuro como sendo passível de planejamento. Fica, então, claro que disposições para agir de um modo economicamente razoável não são atributos gerais ou naturais de um sujeito econômico transcendental, mas dependem de condições históricas e institucionais bem específicas e situadas. Esse é o ponto nodal da explanação bourdieusiana sobre a gênese do capitalismo moderno periférico. Ora, tal subversão do itinerário teórico liberal coloca-nos diante de um problema fundamental: de que modo certo estado mais ou menos durável das práticas econômicas confere acesso à previsibilidade temporal do porvir.

O sub-proletário reflete uma contradição peculiar: além de um passado recente imerso numa cosmologia tradicional enraizada na reprodução simples da natureza, isto é, sem a distinção entre tempo de produção de trabalho, esta classe excluída não dispõe de condições favoráveis para sua inserção no mercado de trabalho moderno, aprofundando sua instabilidade econômica.

O trabalho produtivo se caracteriza por dois fatores principais: a) seu caráter disciplinar, contínuo e estendido no cotidiano; b) a incorporação de conhecimento técnico especializado, sem o qual a constituição de uma divisão do trabalho francamente urbana e industrial seria impossível. A identificação de um critério seletivo do trabalho produtivo na especialização incorre na distribuição da força de trabalho em diferentes setores, bem como o progresso, de modo que a divisão do trabalho se torna mais complexa e novos postos ocupacionais são criados. Em parte, o valor e o reconhecimento socialmente concedidos a um trabalho estão ligados à raridade das competências intelectuais, sociais e técnicas que uma ocupação exige de um trabalhador. 
Esse não é o caso do sub-proletariado, aglomerado em massa em busca de um emprego como estivadores na zona portuária. Assim:

[...] Em uma sociedade onde $87 \%$ dos indivíduos não têm diploma de ensino geral e $98 \%$ nenhum diploma do ensino técnico, a posse de um certificado de aptidão profissional ou de um certificado de estudos primários proporciona uma vantagem enorme na competição econômica; uma diferença ínfima de nível, aquela que separa, por exemplo, um indivíduo que sabe ler e outro que sabe ler e escrever, determinando uma diferença desproporcional nos casos de sucesso social (Bourdieu, 1977, p. 49).

A passagem nos informa sobre como o trabalho exige, no capitalismo moderno, a incorporação de algum capital cultural técnico passível de valorização no sistema produtivo. Do contrário, o trabalhador torna-se relegado às ocupações de exploração corporal direta, podendo ser facilmente substituído por maquinário mais eficiente. Portanto:

[...] para os sub-proletários, toda existência profissional é colocada sob o signo do arbitrário. E, de fato, a ausência de qualquer organização racional da trajetória profissional e a falta de um controle dos processos de recrutamento; certos empregadores podem explorar (ou deixar explorar) o exército de operários desprovidos de uma especialização e preparados para todas as condições para escapar do desemprego (Bourdieu, 1977, p. 50).

O acesso ao trabalho rentável, que muitas vezes alia constância e volume juridicamente garantidos, pressupõe a forma incorporada e objetivada (qualificação) de conhecimento técnico especializado. A especialização condiciona, por sua vez, as chances de organização racional da trajetória profissional.

No que concerne aos estudos sobre o campo econômico, Bourdieu delineia, na obra: As estruturas sociais da economia (2000), as teses básicas sobre uma sociologia das organizações empresariais e sua relação com o estado. Se por um lado o campo econômico acolhe a concorrência como seu modus operandi, ela não ocorre de modo totalmente livre, mas através de pressões no estado, que asseguram, no limite, reservas de mercado e concessões. Isto posto:

O estado fixa regras de funcionamento através de toda regulamentação específica que visam somar uma infraestrutura jurídica (direito de propriedade, direito comercial, direito do trabalho, direito contratual e etc.) e uma regulamentação geral (bloqueio e controle dos preços, enquadramento do crédito e etc.). O mercado é burocraticamente controlado (Bourdieu, 2000, p. 116). 
Por outro lado, se o campo econômico revela sua interpenetração, pelo menos no tocante à sua regulação, pela burocracia estatal, as empresas também constituem espaços institucionais próprios. Tanto dentro de certo setor, na hierarquia de condições de concorrência quanto, em seu funcionamento interno, as empresas não são entidades harmônicas.

Não obstante, uma tomada de posição estratégica sempre é identificável em empresas, principalmente as dominantes em seus setores. Essa tomada de posição não existe sem a construção social de uma demanda e de seus rumos. Eis, aqui, mais uma desavença de Bourdieu com o pensamento liberal: a demanda não é uma ambição espontânea e natural de consumo por parte de um público, mas é resultante do encontro entre a indústria da propaganda, o estilo de vida e de consumo encontrados nas classes sociais. Além de levar em consideração as disposições ou o habitus provável de certo agrupamento de consumidores, a demanda se colocaria sempre em relação às limitações de oferta, ou seja, definindo as condições de acesso a um determinado nicho de mercado. No âmbito da construção social da oferta, Bourdieu (2000, p. 30) ainda sublinha a relação entre política de crédito, o fomento da produção e permissões jurídicas, que, no caso do mercado imobiliário, se deixa entrever nas permissões para construção, nas licitações ganhas, nos regulamentos e etc. Em suma, a oferta materializa um espaço diferenciado de concorrentes no qual cada estratégia empresarial ocorre em relação às tomadas de posição dos adversários e das condições de acesso ao setor de mercado do público alvo em questão.

Desse modo, as mercadorias também cristalizam investimentos simbólicos e culturais, refletindo seu valor estético na hierarquia de classes. Certamente o exemplo mais patente de investimento simbólico são mercadorias de luxo, cuja particularidade reside em denotar, de um lado, uma cláusula de exclusividade em sua aquisição e, por outro, ser objeto de cobiça e desejo por aqueles que não estão em condições de possuí-las.

Ao reconstruir as estruturas sociais do campo econômico, Bourdieu alveja o enquadramento de fatores explicativos que transcendam conceitos excessivamente dedutivos da economia e desloquem a explicação meramente técnica sobre ela própria. Quais seriam as consequências de enxergar a economia não mais como resultante de modelos abstratos? Como seria desmistificar sua filosofia social, baseada no racionalismo clássico de um agente descontextualizado, consciente e isolado? O primeiro avanço certamente seria romper com a validade autônoma de leis econômicas, isoladas de qualquer influência de cenários políticos contingentes. Isto posto, constataríamos que o mercado não é neutro. Em contraste, ele estabelece relações de poder entre 
as empresas e suas chances de dominar recursos econômicos, comunicativos, políticos, tecnológicos e organizacionais. Geralmente, a hegemonia de grandes corporações e empresas transparece na medida em que controlam o tempo das transformações em diferentes domínios, como os acima citados. Elas estão em condições de se antecipar. Quanto mais os mecanismos de encerramento da concorrência operam, tornando seletivo acesso ao lucro real, bem como o ingresso de novos atores econômicos, mais eles se afinam com poder direto de lobby político.

\section{Conclusão: uma tentativa de síntese}

Os esforços teóricos de Simmel e Bourdieu podem ser examinados à luz da desnaturalização da esfera econômica. Sob esse prisma, as duas teorias oferecem realizações e limites à compreensão dos fatores explicativos do cenário atual. De acordo com o arcabouço conceitual de Simmel, por exemplo, encontramos a ambição de uma explicação geral sobre as consequências trágicas de um descompasso entre estrutura social e ação, no qual um meio de troca sem qualidade se torna o fim último de todas as ambições e aspirações. Esse desenvolvimento cultural transforma por completo a sensibilidade perceptiva e o modo de pensar do indivíduo moderno.

Em segundo plano, destaca-se, como vimos, a interconexão entre diferentes grupos, suas condições econômicas e as possibilidades de ação com o dinheiro. $\mathrm{O}$ que diferencia as classes dominantes seria justamente o acesso ao uso potencial do dinheiro enquanto forma de exercício de empoderamento de sua trajetória, dispondo potencialmente de pessoas e mercadorias. Trata-se da ruptura integral com o uso emergencial, mais comum nas classes populares. Tal configuração tornaria factível a compreensão do uso do dinheiro em abstrato e, portanto, habilitando sua função de capital, isto é, como fim. Por estarem socializadas nesse tipo de uso não limitado ao presente, as classes dominantes desenvolvem uma ação econômica prospectiva. Ele está ligado ao que Norbert Elias (1984, p. 20) chamou de determinação ativa do tempo, cujo empoderamento subjetivo aumenta o poder decisório sobre a organização temporal das práticas.

Por outro lado, o grande feito de Bourdieu foi perceber que a experiência temporal linear e racional estava ligada à estabilização das condições econômicas e ao fortalecimento de uma finalidade acumulativa da economia moderna. Ao desnaturalizar a experiência temporal, descarta-se todo seu embasamento num sujeito transcendental. O tempo social, além de não ser uma constante universal, não é percebido da mesma forma por todas as classes. Ao contrário, não é preciso ir muito longe para notar que as classes hierarquizadas 
nos setores inferiores do campo econômico dispõem de intervalo temporal de ação muito diminuto.

$\mathrm{Na}$ tese de doutorado intitulada Para uma sociologia do dinheiro: investigações sobre o habitus econômico de classe (Visser, 2015), notei como condições econômicas de micro comerciantes informais beneficiários do programa CrediAmigo, que, unindo baixo volume e alta variação mensal, encurtam a unidade temporal e o raio de atuação com o dinheiro (Visser, 2015, p. 163). Em contraste, o grande empreendedor, com sua grande empresa, calcula seu ciclo produtivo anualmente (ibid., p. 164). Vale notar que, na pesquisa realizada, a estrutura da renda dos comerciantes, do público de classe média estabelecida e classe alta (economistas, engenheiros e empresários) é bastante distinta: se os pequenos comerciantes unem baixo volume e considerável variação, os entrevistados das classes dominantes geralmente aliam alto volume e estabilidade. Entretanto, quando a renda é instável, o alto volume compensa; quando ela é de baixo volume, normalmente é estável, não afetando sua capacidade de poupança e de pagamento futuro.

No caso dessa fração pequeno comerciante das classes dominadas, a estrutura de sua renda contrapõe-se a um terceiro quesito: os gastos fixos. Foi precisamente esta contradição averiguada por Bourdieu, quando postulou que o sub-proletariado vivia num cosmos econômico objetivo cada vez mais racionalizado, ou seja, exigindo capacidade de despender dinheiro constantemente (ao passo que a subsistência era substituída pelo mercado urbano), mas em meio a circunstâncias econômicas instáveis. Embora não compartilhem de uma percepção temporal pré-moderna, os micro comerciantes aliam estes três quesitos - baixo volume, variação em curto prazo e gastos fixos - cristalizados em sua condição econômica.

Aqui, a relação entre certa configuração das práticas econômicas e a experiência temporal rompe com a ideia estrita do materialismo simplista: não se trata apenas de arrolar o fator econômico enquanto acesso à posse, mas entendê-lo em sua trama significativa. Ora, se o acesso a condições econômicas estáveis corresponde a chances de desenvolver um planejamento racional da própria trajetória (ou pelo menos que seja uma opção viável), então podemos fazer a ilação de que esta afinidade eletiva permite vincular investigações sobre disposições e condições econômicas às outras esferas, como: política, cultura, escola, família e etc. Logo, não se trata de investigar a economia por ela própria.

Ao pesquisar a relação entre disposições econômicas e classes sociais, deparei-me com duas questões: a) o acesso a condições econômicas mediadas por instituições; b) o processo de diferenciação das práticas econômicas, 
iniciado pela constituição de uma retaguarda financeira contínua e de longo prazo ou uma estrutura de renda estável e com bom volume. Ambos podem ser considerados como fatores fortes e conjuntos. A institucionalização de condições e práticas econômicas diz respeito ao acesso que de algumas classes sociais dispõem a redes de proteção econômica para além da posse de dinheiro vivo: renda garantida, acesso a investimentos financeiros, patrimônio rentável ou produtivo são alguns exemplos.

O termo renda garantida (garantiertes Einkommen), de Erich Fromm (1999), refere-se ao salário de bom volume e baixa variação mensal ou volatilidade com reajustes, de maneira a se proteger das flutuações da inflação. Tal advertência justifica-se, dado que a categoria não se aplica simplesmente ao assalariamento, mas às circunstâncias ontológicas por ele abrigadas. Decerto, ele havia imaginado as contradições da expansão da dignidade material do pós-guerra para as classes trabalhadoras e médias, domando as necessidades econômicas no futuro e, assim, mitigando seus efeitos mais nefastos. Do ponto de vista dessa forma básica de estabilização temporal das condições econômicas, os pequenos comerciantes investigados carecem do ingresso nessas condições. Eles não são assalariados e muito menos exibem, na maioria das vezes, uma trajetória profissional concatenada, na qual as diferentes etapas estão mais ou menos conectadas entre si (Visser, 2015).

Com o acesso às formas institucionalizadas da ação econômica através de bancos, como investimentos financeiros, patrimônio rentável e produtivo, as classes dominantes, sobretudo a elite econômica, experimentam o afrouxamento e o relaxamento do controle disciplinado das necessidades materiais. Não é arbitrário notar a ausência de traços de rigorismo econômico nas classes dominantes quando se adentra temas como poupança e investimento financeiro (Visser, 2015, p. 157). Tais condições confortáveis não mais hierarquizam diretamente despesas, constrangendo aquilo que Niklas Luhmann (1994, p. 14) chamou de capacidade de pagamento, mas horizontalizam-nas, ao passo que a capacidade de poupança e pagamento imediato se tornam relativamente independentes e não mais tencionam uma a outra. Elas tornamse simultaneamente acessíveis.

Porém, o conceito de diferenciação social ao qual nos afinamos, reside na obra de Simmel (1989). Sua premissa básica era de que o adensamento do nível social se tornava cada vez mais forte à medida que a participação de um indivíduo numa miríade círculos sociais era garantida. Sob esse prisma: "A possibilidade da individualização aumenta incomensuravelmente na medida em que a mesma pessoa simultaneamente pertence a vários círculos, assumindo diferentes posicionamentos relativos" (Simmel, 1989, p. 476). 
No mundo moderno, nenhuma das posições ou funções relativas englobam a personalidade por completo, libertando-a da fusão identitária total com a coletividade. Assim: "[...] Quanto mais elevado é o espírito, mais ele se diferencia plenamente [...]" (Simmel, 1989, p. 196). Como consequência, desenvolvem-se seu engajamento e perfilhação através de formas mais complexas de socialização e aprendizado, bem como seu aparato psíquico torna-se diferenciado, capaz de manejar ponderadamente inúmeros pontos de vista, operar distinções e perceber nuances cognitivas (ibid., p. 213). Isto posto, Simmel admite que o desenvolvimento da vida individual depende do aprofundamento e da extensão dos vínculos de pertencimento.

A integração no campo econômico depende, para uma parcela considerável das classes, da relação entre a citada estrutura da renda e sua relação com gastos fixos. A estrutura da renda mais incidente nas classes populares, que combina baixo volume e alta variação, confere um sentido prático à despesa, de modo a reforçar seu caráter emergencial, contencioso e defensivo. Suas condições obrigam uma hierarquização precoce de prioridades econômicas.

Processo similar ocorre na dinâmica entre condições e práticas econômicas. A diferenciação das práticas econômicas e o desenvolvimento decorrente de suas camadas secundárias ocorrem cada vez que a ação relativa ao capital econômico se torna paulatinamente mais centrífuga, alargando o seu campo de aplicabilidades. Sua penetração pode acontecer em vários ramos da vida social, sem que um coloque o outro em xeque, sem que um ramo entre em atrito com o outro. Sob esse espectro, a independência relativa entre as práticas, não mais subordinadas a finalidades pré-estabelecidas, torna factível a coexistência mais ou menos pacífica de consumo, capacidade de poupança, endividamento, investimentos financeiros, aquisição de patrimônio rentável e etc., sem que uma ponha em risco a outra. Trata-se da constituição de planos e camadas complementares de ação dentro do patrimônio de disposições (Lahire, 2001). Logo, a ação econômica não se limita mais previamente, abrindo um leque de usos interdependentes e especializados entre si. Ao libertar-se das finalidades sistêmicas postas pelas urgências econômicas, as classes dominantes estão, portanto, em condições de agir "em rede" com o capital econômico na medida em que os usos particulares não entram em conflito entre si (Visser, 2015, p. 195-197).

A diferenciação das práticas mantém uma afinidade com o uso prospectivo do dinheiro, fazendo as classes médias, por exemplo, perceberem o futuro como investimento, principalmente no tocante à educação e à saúde. Para eles, algumas despesas se colocam como prospectivos e fixos, enquanto que na classe trabalhadora nota-se seu caráter emergencial 
e instável (Krause, 2016, p.314-315). A transformação do sentido cotidiano empregado ao gasto pressupõe uma compreensão pré-reflexiva da hierarquia de prioridades, contrapostas aos limites impostos pelas condições econômicas. A relação entre vida interior e economia monetária estrutura-se, portanto, segundo padrões diferenciais de classe.

Nesse caso, a dominação econômica não apenas se caracterizaria pela distribuição desigual das diversas espécies de capitais no campo econômico, mas igualmente das pré-condições sociais que coordenam a dinâmica entre contextos e práticas, de modo que distintas classes sociais encontram-se em condições de orientar suas práticas econômicas ao futuro no longo prazo. Isso implica em afirmar que o acesso ao comportamento diferenciado com o dinheiro é objeto de lutas e disputas.

Em quase todos os entrevistados de classe média estabelecida (advogados, economistas, engenheiros e consultores) foi encontrada a conversão de uma poupança de longo prazo em investimento financeiro de baixo risco ou em imóveis (aluguéis). São estratégias de investimento com uma finalidade ligada ao dinheiro em sua forma potencial. Quando adentramos o horizonte dos pequenos comerciantes, a noção de investimento ganha um contorno mais concreto, ligado ao projeto da moradia ou do próprio negócio (diversificação de mercadorias e empregar auxiliares). Assim, ele raramente ganha um sentido financeiro.

$\mathrm{O}$ artigo buscou contribuir para uma teoria de classes arrolando a relação entre práticas econômicas e seu desenvolvimento desigual nas classes sociais. O sentido do dinheiro não prescinde, portanto, do sujeito econômico prático, concreto e engajado em circunstâncias objetivas visíveis. Todavia, práticas econômicas não são mero epifenômeno de condições econômicas objetivas. Se nas duas partes do artigo buscamos reconstruir as principais questões de Simmel e Bourdieu com relação à esfera econômica, na última, a questão fundamental foi interconectar tais preocupações com a construção de premissas para uma teoria das práticas econômicas.

\section{Referências}

BOURDIEU, Pierre. Algérie 60: structures économiques et structures temporelles. Paris: Les Éditions de Minuit, 1977.

BOURDIEU, Pierre. Les structures sociales de l'économie. Paris: Éditions du Seuil, 2000.

BOYER, R. La antropología económica de Pierre Bourdieu: su contribuición al análisis de la economía y el cambio. Guadalajara: University Press from the South, 2015. p. 9-70. 
DURKHEIM, Émile. As regras do método sociológico. São Paulo: Martins Fontes, 2007.

ELIAS, Norbert. Über die Zeit. Frankfurt am Main: Suhkamp Taschenbuch Verlag, 1984 [Sobre o tempo. Rio de Janeiro: Editora Jorge Zahar, 1998].

HONNETH, Axel. Arbeit und instrumentales Handeln: kategoriale Probleme einer kritischen Gesellschaftsheorie. In: Axel Honneth; Urs Jaeggi (Org.). Arbeit, Handlung und Normativität: Theorien des Historischen Materialismus. Frankfurt am Main: Suhrkamp, 1980. p. 185-225

HONNETH, Axel. Trabalho e reconhecimento: tentativa de uma redefinição. Civitas, v. 8 , n. 1 p. $46-67,2008<10.15448 / 1984-7289.2008 .1 .4321>$.

FRISBY, David. Fragments of modernity: theories of modernity in the work of Simmel, Kracauer and Benjamin. Massachusetts: MIT Press,1986.

FROMM, Erich. Psychologische Aspekte zur Frage eines garantierten Einkommens für alle. In: Gestamtausgabe in zwölf Bänden. Rainer Funk (Org.). München: Deutscher Taschenbuch Verlag 1999.

KRACAUER, Siegfried. Das Ornament der Masse. Frankfurt am Main: Suhrkamp, 1977. p. 210-247 [O ornamento da massa. São Paulo: Cosac Naify, 2009].

KRAUSE, Mercedes. La temporalidad del dinero: um mecanismo de reproducción sociocultural de las desigualdades sociales. Civitas, v. 16, n. 2, p. 306-322, 2016 $<10.15448 / 1984-7289.2016 .2 .22844>$.

LAHIRE, Bernard. De la théorie de l'habitus à une sociologie psychologique. In: Bernard Lahire (Org.). Le travail sociologique de Pierre Bourdieu: dettes et critiques. 2. ed. Paris: La Découverte, 2001. p. 121-152.

LUHMANN, Niklas. Die Wirtschaft der Gesellschaft. Frankfurt am Main: Suhrkamp Verlag, 1994. p. 7-350.

LUHMANN, Niklas. La economía de la sociedad como sistema autopoético. Revista Mad, n. 29, p. 1-25, 2013.

NEDELMANN, Birgitta. Psychologismus oder Soziologie der Emotionen? Max Webers Kritik an der Soziologie Simmels. In: Otthein Rammstedt (Org.). Simmel und die frühen Soziologuen: nähe und Distanz zu Durkheim, Tönnies und Max Weber. Frankfurt am Main: Suhrkamp, 1988. p.11-36.

REHBEIN, Boike Reproduktion sozialer Ungleichheit in Deutschland. Konstanz: UVK, 2015.

SIMMEL, George. Über Geiz, Verschwendung und Armut. Ethische Kultur, Wochenendezeitschrift für sozial-ethische Reformen. v. 7, n. 42, p.332-335; e v. 43, p. 340-341, 1899.

SIMMEL, George. Philosophie des Geldes. Köln: Anaconda Verlag, 2009.

SIMMEL, George. Philosophie der Mode, die Religion, Kant und Goethe, Schopenhauer und Nietzsche. Frankfurt am Main: Suhrkamp, 1995.

SIMMEL, George. Soziologie: Untersuchungen über die Formen der Vergesellschaftung. Frankfurt am Main: Suhrkamp, 1992a [Sociología: estudios sobre las formas de socialización. Buenos Aires: Fondo de Cultura Económica, 2014]. 
SIMMEL, George. Über die soziale Differenzierung. Gesammte Ausgabe (Aufsätze 1887 bis 1890). Heinz Jürgen Dahme; Otthein Rammstedt (Org.). Frankfurt am Main: Surhkamp, 1989.

SOUSA, Antonio Paulino de. Sociologia econômica e história no pensamento de Bourdieu. Perspectivas: revista de ciências sociais, v. 41, p. 169-192, 2012.

UNGER, Roberto Mangabeira. False necessity: anti-necessitarian social theory in the service of radical democracy. London: Verso, 2001.

VISSER, Ricardo. Para uma sociologia do dinheiro: investigação sobre o habitus econômico de classe. Juiz de Fora, 2015. Tese (Doutorado) - Instituto de Ciências Humanas, Universidade Federal de Juiz de Fora.

Recebido em: 5 dez. 2016

Aprovado em: 7 jul. 2017

Autor correspondente:

Ricardo Visser

Rua Presidente Carlos de Campos, 36, ap. 403 - Laranjeiras

22231-080 Rio de Janeiro, RJ, Brasil 